\title{
Consumo sob duas rodas: a bicicleta e o incremento da economia local
}

\section{Consumption under two wheels: the bicycle and the growth of the local economy}

\author{
Larissa Cavalcante Albuquerque ${ }^{1}$ \\ Karla Vanessa Nogueira Maia Amorim² \\ Evangelina da Silva Sousa ${ }^{3}$ \\ Raimundo Eduardo Silveira Fontenele ${ }^{4}$
}

\section{Resumo}

Tendo em vista as políticas de mobilidade urbana e a problemática ambiental que resultaram na criação de infraestrutura para a disseminação da bicicleta como alternativa sustentável para locomoção e de fomento a economia urbana local. Esta pesquisa buscou delinear o perfil dos sujeitos usuários desse tipo de modal, investigar os segmentos de mercado fomentados pela economia da bicicleta e identificar a percepção dos empresários em relação a seus clientes, na cidade de Fortaleza (CE). A metodologia utilizada é de cunho quali-quantitativa. A técnica utilizada para tratamento dos dados qualitativos foi análise de conteúdo, e os dados quantitativos foram suportados pela estatística descritiva e análise de cluster. Foi aplicado um questionário com 132 usuários desse tipo de modal e realizadas entrevistas com proprietários ou gerentes de estabelecimentos que atuam na comercialização e serviços de manutenção de bicicletas. Como resultados foram identificados dois clusters distintos, sendo o cluster 1 formado por respondentes que possuem bicicleta, predominantemente do gênero feminino, enquanto no cluster 2, também prevalecem respondentes do gênero feminino, no entanto, são

\footnotetext{
${ }^{1}$ Mestre em Administração e Controladoria, Coordenadora Acadêmica do Centro Universitário Fanor Wyden (UNIFANOR).

${ }^{2}$ Mestre em Administração e Controladoria, Docente no Centro Universitário Fanor Wyden (UNIFANOR)

${ }^{3}$ Doutoranda no Programa de Pós-graduação em Administração e Controladoria da Universidade Federal do Ceará (UFC), Administradora na Universidade Federal do Piauí (UFPI).

${ }^{4}$ Doutor em Ciências Econômicas, Docente no Programa de Pós-graduação em Administração e Controladoria da UFC.
} 
mais jovens e não possuem bicicleta própria. O segmento de mercado mais fomentado pelos usuários é do ramo de ciclismo, pois identificaram-se aquisições em maiores proporções que os demais segmentos. Apenas os comerciantes especializados em venda e serviços perceberam incrementos nos seus negócios, devido à expansão da infraestrutura específica e à cultura de mobilidade urbana instituída pelas políticas públicas da Prefeitura de Fortaleza nos últimos anos.

Palavras-chave: Bicicleta. Desenvolvimento Local. Economia Urbana.

\begin{abstract}
Because of the urban mobility policies and the environmental problem which resulted in the creation of infrastructure for the dissemination of the bicycle as a sustainable alternative for locomotion and the formation of the local urban economy. This research sought to outline the profile of the subjects who use this type of modal, to investigate the market segments which are fomented by the bicycle economy and to identify the perception of entrepreneurs about to the bicycle users as clients in Fortaleza city (CE). The methodology used is of a qualitative and quantitative nature. The technique used to treat qualitative data was content analysis, and quantitative data was supported by descriptive statistics and cluster analysis. It was applied a questionnaire to 132 users and conducted interviews with owners and managers who work in the marketing and maintenance of bicycle service. As a result, were identified two distinct clusters. The cluster one formed by those who possess a bicycle, in its majority-female gender. The cluster two, also the female majority who are younger and do not possess their bicycle. The market segment most fostered by users is in the cycling industry, as acquisitions were identified in greater proportions than the other segments. Only merchants specialized in sales and services noticed increases in their business, due to the expansion of specific infrastructure and the culture of urban mobility established by the public policies of the Fortaleza city in recent years.
\end{abstract}

Keywords: Bicycle. Local development. Urban economy.

\title{
Introdução
}

A bicicleta emergiu nos últimos anos como uma alternativa em busca da mobilidade urbana sustentável. O Ministério das Cidades publicou em 2007 um caderno de referência, 
para elaboração de planos de mobilidade por bicicletas nas cidades brasileiras, com a finalidade de auxiliar os municípios a implantarem um plano cicloviário a ser incorporado aos transportes existentes a fim de fortalecer a importância da utilização de modos coletivos para deslocamento.

A política nacional de mobilidade urbana propõe a inclusão da bicicleta nos deslocamentos urbanos como forma de inclusão social, de redução e eliminação de agentes poluentes e de melhoria da saúde da população. No entanto, a integração da bicicleta ao sistema de circulação atual requer infraestrutura, por meio da construção de ciclovias, ciclofaixas e vias cicláveis (vias de tráfego compartilhado para o uso seguro da bicicleta), além de reflexões sobre uso e ocupação do espaço urbano (Ministério das Cidades, 2007).

Vale ressaltar que a imagem da bicicleta como um meio de transporte de indivíduos de baixa renda e desvalorizado perante outros modais reflete na sua forma de utilização (Silveira \& Maia, 2013). É necessário promover a imagem da bicicleta como um modal de uso frequente e não apenas para lazer, além de investigar os impedimentos e as motivações à utilização da bicicleta, por parte dos usuários e introduzi-la no sistema de transporte urbano (Franco, 2011; Silveira \& Maia, 2013).

A utilização da bicicleta, como meio de transporte, proporciona algumas vantagens: benefícios à saúde, modo mais econômico e rápido para locomoção, baixo impacto ambiental, baixo custo de infraestrutura (Olekszechen, Battiston, \& Kuhnen, 2016).

Estudos realizados em Portugal demonstraram que a promoção do uso da bicicleta, por meio de projetos e iniciativas, trouxeram duas mudanças importantes: a primeira refere-se a alterações nos padrões de deslocamento por meio da criação e da melhoria da infraestrutura local, enquanto a segunda, menos evidente, envolve a valorização econômica da bicicleta, compreendendo desde a cadeia produtiva até as motivações distintas de utilização do modal (deslocamento, desporto, lazer ou turismo), cujas necessidades e efeitos são desconhecidos (Mota \& Sá, 2013).

Pesquisas da Smart Growth America (2013) revelaram que empresários locais de São Francisco (Califórnia) perceberam um aumento das vendas em torno de $60 \%$ e tal crescimento foi atribuído aos clientes que utilizam a bicicleta, como meio de transporte urbano, e aos que optaram pela caminhada - opções de transporte que afetaram a quantidade de viagens realizadas e, consequentemente, o consumo.

Para Schoner, Harrison e Wang (2012), os gastos ocasionados pela utilização de determinado meio de transporte são de difícil mensuração, posto que são disseminados entre várias categorias de despesas que não são rastreadas, o que impossibilita a estimação.

Revista Gestão e Secretariado (GeSec), São Paulo, SP, 12(1), jan./abr., 2021, p. 79-105. 
Nesse contexto, questiona-se acerca da movimentação econômica provocada pela utilização das bicicletas, diante da infraestrutura oferecida pelo município de Fortaleza, considerando-a como um recurso necessário para a mobilidade urbana sustentável e como um meio democrático de oferta de transporte urbano a população (Castro, Barbosa, \& Oliveira, 2013).

Uma vez que as pesquisas realizadas avançam na discussão sobre o uso da bicicleta sob a ótica da mobilidade urbana sustentável (Castro et al., 2013; Coelho, Vilas, Silva, \& Pereira, 2015; Diógenes, Araújo, Tassigny, \& Bizarria, 2017), como meio de transporte (Araújo, Oliveira, \& Santos, 2009; Providelo \& Sanches, 2010; Olekszechen et al., 2016, Patricio \& Kruszielski, 2016), e identificação de valores que influenciam em sua utilização (Forward, 2014; Passafaro et al., 2014; Silveira \& Maia, 2015), o presente estudo traz uma nova perspectiva, ao abordar sobre a movimentação econômica estimulada por usuários de bicicletas, e por meio dos clusters foi possível segmentar os sujeitos de acordo com os perfis e assim, estabelecer análises que envolvam a utilização do espaço urbano (Németh, 2009; Edra, Costa, \& Fernandes, 2015) e mobilidade urbana sustentável.

Muito embora exista uma literatura sobre o uso da bicicleta e seus impactos em diferentes regiões e países, tem sido crescente o interesse sobre o perfil dos usuários, suas percepções e motivações, destacando-se os aspectos relacionados aos impactos das ações das políticas públicas e empresas. A maioria dos estudos é oriunda da Europa e América do Norte e são raros os estudos que contemplem temas envolvendo os diversos usuários no contexto da mobilidade por bicicleta. Neste contexto, o presente estudo visa contribuir para o entendimento dos seguintes questionamentos: Os usuários de bicicleta fomentam a economia local? Quais as percepções dos empresários locais em relação à implantação de ciclovias e outras ações que induziram a utilização da bicicleta como meio de transporte na cidade de Fortaleza?

Para responder tais questionamentos, foram delineados os seguintes objetivos: i) delinear o perfil dos sujeitos usuários de bicicleta; ii) investigar os segmentos de mercado fomentados pela economia da bicicleta; e iii) avaliar a percepção dos empresários em relação aos usuários desse tipo de modal como clientes e sobre a infraestrutura implantada na cidade de Fortaleza (CE). Para tanto, realizou-se análise qualitativa e quantitativa junto a 141 participantes, sendo 132 usuários de bicicletas e 9 gerentes ou proprietários de empresas locais. Pela relevância do tema, este estudo se propõe a ampliar o conhecimento sobre essa temática, além de contribuir para a adoção de políticas públicas que potencializem o uso desse 
tipo de modal, e estratégias que vinculem a infraestrutura cicloviária ao cotidiano dos cidadãos, de forma a atender aos interesses dos mais diversos setores.

\section{Desenvolvimento Local}

Segundo Andion (2003), movimentos de reestruturação das bases de regulação econômica, política e social influenciaram a redefinição do conceito de desenvolvimento, que culminou com uma ressignificação multidimensional, relacionada à sustentabilidade (desenvolvimento sustentável), território (desenvolvimento local), participação cidadã (sociedade como protagonista do processo de desenvolvimento) e valores éticos (desenvolvimento baseado em valores). Tal ressignificação implica em uma maior amplitude do conceito de desenvolvimento, posto que deixa de ser sinônimo de crescimento econômico (Andion, 2003) e contribui para "a inclusão da sociedade civil nas intervenções governamentais" (Simão et al., 2017, p. 289).

A participação de agentes sociais e da institucionalidade da localidade, por meio da diversidade e das potencialidades ambiental, cultural, econômica e social atuam para a transformação e o desenvolvimento de determinado local (Monteiro \& Monteiro, 2006; Martins, Vaz, \& Caldas, 2010;).

O desenvolvimento envolve ações proativas, reconhecimento e ativação de recursos endógenos que instaure operações autônomas, suscitado de dentro para fora, sendo qualitativo e multidimensional (Sausen, Patias, \& Allebrandt, 2011; Ferrarini, 2012). Fixa-se nas condições locais e a capacidade de gerar novos conhecimentos institui o elemento central no processo de produção, competição e crescimento (Diniz, Santos, \& Crocco, 2006).

O "local" refere-se a território e delineia-se por meio de potencialidades e necessidades de uma determinada comunidade (Ferrarini, 2012), e compreende um conjunto de relações que existe em um ambiente territorial, considerando suas heterogeneidades (Martins \& Caldas, 2009). Passador e Passador (2010) destacam que a mobilização dos fatores de produção e o potencial interno de determinada região são condicionados à capacidade de liderança e condução da sociedade em prol do desenvolvimento local.

Mister, também se faz considerar a sociedade civil, suas formas locais de solidariedade, integração social e civismo como a principal agente da modernização e da transformação socioeconômica em uma região (Andion, 2003; Passador \& Passador, 2010)

Todavia, além de transformações nos modos de produção e na tecnologia, o desenvolvimento econômico interfere nas instituições políticas sociais e econômicas, sendo 
necessária a interação entre o poder público local, empresas e sociedade (Muls, 2009). Simão et al. (2017) destacam que o desenvolvimento local compreende a busca por melhor qualidade de vida e por meio da parceria entre agentes locais governo, as políticas públicas passam a ser norteadas pelo enfoque emancipatório.

Neste contexto, apresentam-se as políticas públicas de apoio ao uso da bicicleta em Fortaleza e aspectos referentes à economia local movimentada pela sua utilização.

\subsection{Políticas públicas para o uso de bicicletas}

Nas últimas décadas, o Brasil apresentou um avanço no que se refere às políticas públicas de apoio ao transporte cicloviário. Ainda em 2007 foi publicado o Programa Brasileiro de Mobilidade por Bicicleta, o Bicicleta Brasil, que tinha como principal objetivo estimular governos municipais e estaduais a implantar e aprimorar ações que promovessem o ciclismo como opção segura nos deslocamentos urbanos (Ministério das Cidades, 2007). Neste tópico não se pretende esgotar o tema, mas expor algumas das ações que fomentaram o uso da bicicleta como meio de transporte em Fortaleza, fundamentando o trabalho de campo e a análise dos dados coletados na pesquisa.

A saturação de automóveis nos grandes centros gera percalços para a mobilidade urbana, além de problemas ambientais. No Brasil, datam da década de 1970, após o grande acréscimo nos preços dos combustíveis conhecido como $1^{\circ}$ Choque do Petróleo, as primeiras iniciativas do Governo Federal para promover um planejamento cicloviário e políticas para o uso de bicicletas. Já nos anos 80, várias cidades idealizaram planos diretores de transportes urbanos com ações voltadas para a melhoria da circulação e segurança de ciclistas (Ministério das Cidades, 2007).

Na capital do Ceará, tais incentivos aconteceram de forma incipiente por meio do Plano Diretor Cicloviário de Fortaleza, em 1981, que continha as diretrizes para a implementação das primeiras ciclovias da cidade, além de orientações para a expansão futura, o que acabou acontecendo de forma tímida e desconectada. Já em 2013, um novo documento intitulado Plano Diretor Cicloviário Integrado (PDCI) foi concluído e a lei regulamentadora decorrente aprovada em dezembro de 2014 (Instituto de Planejamento de Fortaleza [IPLANFOR], 2015). No entanto, somente a partir de 2015 ações efetivas começaram a ser implementadas.

O PDCI regulamenta todas as ações cicloviárias da cidade e indica políticas de atuação e gerenciamento de obras na área por um período de 15 anos, prevendo a implementação de 
uma rede de 276 quilômetros de ciclovias, 122 quilômetros de ciclofaixas, 4 quilômetros de passeios compartilhados e Zonas 30, vias com limite velocidade de veículos até $30 \mathrm{~km} / \mathrm{h}$. Outros equipamentos relevantes previstos no plano são os bicicletários e os paraciclos a serem implantados nos principais pontos da cidade, como terminais de transporte público, estações de trem ou metrô, instituições de ensino, entre outros. Além de recomendações sobre infraestrutura, o PDCI comporta instruções de outras políticas públicas de incentivo à mobilidade sustentável em Fortaleza, tais como: Projeto da Ciclofaixas de Lazer, o Sistema de Bicicletas Compartilhadas (Bicicletar), ações de educação, incentivo e fiscalização, bem como a criação de uma coordenadoria de gestão cicloviária dentro da estrutura organizacional da prefeitura de Fortaleza (Iplanfor, 2015).

Visando promover o uso da bicicleta em atividades de recreação e cultura, a Ciclofaixa de Lazer foi iniciada em setembro de 2014 (Iplanfor, 2015) com o apoio da Autarquia Municipal de Trânsito (AMC), da Empresa de Transporte Urbano de Fortaleza (ETUFOR) e da Secretaria Municipal de Conservação e Serviços Públicos (SCSP). Em 2016, após ampliações, a ciclofaixa já era composta por cerca de $21 \mathrm{~km}$ de rotas separadas por cones ligando diversos pontos da cidade aos domingos, das 7h às 13h (Tribuna do Ceará, 2016).

Como um dos destaques do PDCI, ao final de 2014 era inaugurado o Bicicletar Sistema de Bicicletas Compartilhadas de Fortaleza, com 15 estações em sua fase inicial. Após apenas quatro meses o programa se consolidou, chegando ao topo do ranking de cidades brasileiras com o maior número de viagens por dia (O Povo Online, 2015). Já em 2016 o Bicicletar possuía 80 estações e 800 bicicletas, com meta de totalizar 300 estações até 2018 . (O Povo Online, 2016).

A fim de coordenar estas e outras ações previstas no PDCI, a criação da Coordenadoria de Gestão Cicloviária (COCICLO) foi outro esforço para consolidar tal movimento: “[...] a existência de uma unidade gerencial específica para o modal cicloviário é uma demanda antiga e muito importante para o planejamento e implantação de medidas de incentivo ao transporte por bicicleta" (Iplanfor, 2015, p. 58).

Importante salientar que o PDCI é uma das diversas ações contempladas pelo Plano de Mobilidade de Fortaleza (PlanMob), um esforço macro que reúne políticas que garantam, de forma participativa, a redução de desigualdades sociais, a acessibilidade e a otimização do deslocamento de pessoas, priorizando o transporte público não motorizado. 


\subsection{Economia da bicicleta}

Para Coelho, Vilas, Silva e Pereira (2015) os projetos de urbanismo utilizados pelas grandes cidades são voltados para o uso de transportes poluentes e individualistas ocasionando uma série de problemas para suas populações. Para estes autores, os gestores precisam realizar ações que visem à preservação ambiental e a qualidade de vida das populações.

Embora a bicicleta tenha, para algumas pessoas, certas desvantagens, sendo vista como um transporte frágil, desconfortável e inseguro, há de se pensar também nos aspectos positivos, pois existem vantagens econômicas, ambientais e de saúde, tais como: evitar o uso de transportes públicos de má qualidade ou ter que enfrentar longos engarrafamentos. Os autores concluem que, conforme eles verificaram em estudos em diversas cidades pelo mundo, a exemplo de Copenhague, os prejuízos econômicos causados pelos transportes tradicionais, sofridos pela população e pelo próprio Governo, influenciam na migração do uso desses métodos tradicionais de transporte para a bicicleta (Coelho et al., 2015).

Países como Japão, Holanda, Alemanha e Inglaterra, que possuem alta renda per capita, incentivam o uso da bicicleta integrada ao transporte coletivo e aos espaços públicos, além de estabelecerem políticas que inibem o uso do automóvel como meio de transporte. Tais iniciativas, aliadas às políticas de aproveitamento do solo e de desenvolvimento, possibilitam a existência de ruas mais seguras e confortáveis para pedestres e ciclistas, promovendo concomitantemente o convívio social. Esse movimento em prol do uso de bicicletas como meio de transporte promove inclusão social, redução da poluição, melhoria da saúde pública e da qualidade de vida, contribuindo para o estabelecimento de cidades sustentáveis e promovendo o desenvolvimento urbano. (Instituto de Energia e Meio Ambiente, 2010)

Segundo Milheiro (2016), países ditos amigos das bicicletas verificaram uma redução da poluição, dos ruídos, dos engarrafamentos e, têm como consequência, a melhora na saúde e na qualidade de vida de sua população. Para o autor, a maior utilização da bicicleta reduz o uso de combustíveis fósseis, as despesas com saúde e gastos associados com automóveis no percurso para a escola e para o trabalho. Estudo desenvolvido por Mason, Fulton e McDonald (2015) concluiu que um dramático incremento no uso de bicicleta pode fazer com que a sociedade mundial economize entre 2015 e 2050, cerca de US\$ 24 trilhões, além de cortar cerca de $11 \%$ das emissões de $\mathrm{CO} 2$ geradas pelo transporte de passageiros nesse mesmo período. 
A fim de verificar o impacto do uso de bicicleta na economia local, Schoner et al. (2012), em estudo realizado sobre o sistema de bicicletas compartilhadas em Minnesota, verificaram que a atividade da estação de bicicleta compartilhada tinha influência positiva e significativa nos negócios da área de alimentação, localizados nas proximidades da estação, embora não tenham encontrado significância relacionada com outros tipos de empreendimentos. Para os autores, a disponibilidade de estações de bicicletas para uso público afeta os padrões de consumo, ainda que não se saiba a proporção desses efeitos. Especialmente nas áreas ao redor das estações de compartilhamento de bicicletas ocorre um maior acesso das pessoas a estas áreas, o que influencia na economia desses locais.

Resultados da pesquisa desenvolvida por Bowles, Fleming, Fuller, Lankford e Printz (2011) indicaram que a bicicleta tem o potencial de gerar benefícios econômicos, sociais, pessoais e de saúde para a comunidade. Estes autores, buscando identificar os impactos na economia e na saúde, levantaram dados acerca do perfil dos usuários de bicicleta e dos gastos que esses ciclistas faziam no percurso para cálculo do impacto econômico desses gastos.

Em estudo realizado em Portugal, verificou-se que juntamente com o aumento do uso da bicicleta como meio de transporte, surge um conjunto de atividades econômicas relacionadas com o modal, tais como: eventos turísticos e de lazer, lojas de venda de bicicletas e oficinas especializadas, lojas de roupas e acessórios para ciclistas, desenvolvimento de infraestrutura e equipamentos de apoio (a exemplo da gestão de infraestrutura para bicicletas, da gestão de sistemas coletivos de bicicletas e de estacionamentos), produção, montagem e adaptação de acessórios, aluguel de bicicletas, além da organização de eventos e atividades complementares (Mota \& Sá, 2013).

A Smart Growth America (2013) salienta que facilitar as condições para que residentes e visitantes possam caminhar ou andar de bicicleta estimula a economia local. Esses valores economizados pela população são redirecionados para a economia local, de forma que as pessoas passam a gastar em habitação, restaurantes e entretenimento.

De acordo com European Cyclist's Federation (2015), após a crise de 2008, a questão de trabalho e emprego tornou-se prioridade nas políticas da União Europeia, o que fez com que a Federação encomendasse pesquisa acerca da contribuição do setor de ciclismo na criação de empregos na Europa. Esse estudo mostrou que o emprego no ciclismo está em grande parte associado à indústria do turismo, especialmente em alimentos, bebidas e alojamento, estimando-se que a contribuição da economia de bicicletas é da ordem de 205 bilhões de euros por ano na União Europeia. De acordo com a instituição, estudos mostram 
que os ciclistas gastam mais na economia local, em comparação com outros modelos de transporte.

\section{Delineamento Metodológico}

Richardson (2012) considera que existem duas abordagens e/ou métodos de investigação: quantitativo e qualitativo. Nessa perspectiva, esta pesquisa utilizou ambas as abordagens, para o alcance dos objetivos propostos, caracterizando-se como um levantamento, ou survey, do tipo analítico, uma vez que se propôs a investigar a existência de relação entre diferentes variáveis (Collis \& Hussey, 2005).

A coleta de dados primários envolveu duas etapas: aplicação de questionários com usuários de bicicletas e realização de entrevistas com proprietários ou gerentes que possuem ou não ações ou campanhas para atrair os ciclistas para seus estabelecimentos e com proprietários ou gerentes que atuam na comercialização e serviços de manutenção de bicicletas e acessórios.

Um dos instrumentos utilizado para coleta de dados primários foi um questionário estruturado contendo 22 questões, adaptado de Schoner et al. (2012), uma vez que tais autores realizaram uma pesquisa que investigou a atividade econômica local associada aos programas de compartilhamento de bicicletas em Minnesota (EUA). O instrumento foi pré-testado, com a finalidade de evidenciar possíveis falhas ou inconsistência e não passou por ajustes.

Os respondentes da pesquisa (etapa quantitativa) foram usuários de bicicletas, envolvendo indivíduos que possuem esse tipo de modal ou utilizem as bicicletas compartilhadas disponíveis na cidade de Fortaleza-CE.

A coleta de dados foi realizada no período de 30 de novembro a 29 de dezembro de 2016. O questionário foi disponibilizado nas redes sociais e enviado por e-mail. 140 questionários foram respondidos, porém 08 foram excluídos por estarem incompletos, resultando em 132 questionários válidos, que compuseram a amostra final. Para alcançar os objetivos propostos, a análise de dados foi realizada utilizando-se da estatística descritiva e análise de clusters por meio do software estatístico Statistical Package for the Social Sciences (SPSS) versão 20.

Em relação à etapa qualitativa, os dados foram coletados por meio de entrevista semiestruturada. Segundo Gray (2012), esse tipo de entrevista proporciona um maior aprofundamento das visões dos respondentes e respostas mais detalhadas. Os sujeitos da 
pesquisa, envolvidos nesta etapa, foram determinados por meio de amostragem não probabilística intencional (Richardson, 2012).

Foram selecionados nove estabelecimentos, do ramo de varejo e serviços, localizados nas imediações de ciclovias e ciclofaixas da cidade, bem como próximos a locais de concentração de passeios ciclísticos, nos bairros Benfica, Cocó e Montese, na cidade de Fortaleza (CE).

A amostra englobou um mercadinho (segmento mantimentos e compras), uma cafeteria e dois restaurantes (segmento alimentação), um bar (segmento lazer e cultura) e quatro empresas do ramo de vendas e serviços de bicicletas. Todos os estabelecimentos possuem mais de dois anos no mercado local e o mais antigo funciona há 20 anos no mesmo local. As entrevistas foram realizadas nos meses de janeiro e fevereiro de 2017, e foram gravadas com consentimento dos entrevistados.

Para fins de confidencialidade da identidade dos sujeitos da pesquisa, optou-se por nomeá-los de forma codificada e aleatória por: E1, E2, E3, E4, E5, E6, E7, E8 e E9. A descrição do perfil dos entrevistados não identificou as empresas em que trabalhavam nem cargos ou departamentos específicos.

Os dados obtidos, por meio das entrevistas, foram analisados por meio da técnica de análise de conteúdo que possibilitou a análise de dados qualitativos com o objetivo de explorar opiniões e representações sociais sobre o objeto de pesquisa (Gomes, 2012).

\section{Resultados e Discussão}

O perfil dos respondentes quanto ao gênero foi de 53\% do gênero feminino e $47 \%$ do masculino. Os respondentes com idade de 18 a 30 anos, respondem por $56 \%$ da amostra, $66 \%$ possui graduação completa, sendo que destes $31 \%$ são pós-graduados. Por meio desses dados, infere-se que a maior parte dos participantes é jovem e possui nível educacional elevado. Em relação aos rendimentos, 18\% dos respondentes informaram não possuir renda, enquanto $41 \%$ estão enquadrados na faixa de renda compreendida entre $\mathrm{R} \$ 1.000,00$ e $\mathrm{R} \$$ $5.000,00,22 \%$ está compreendido entre R $\$ 1.000,00$ e $16 \%$ está compreendido entre $\mathrm{R} \$ 5.000,00$ e $\mathrm{R} \$ 10.000,00$.

\subsection{Caracterização dos sujeitos usuários de bicicletas}


Utilizou-se a técnica de análise de conglomerados não hierárquicos, método $K$-means, visando agrupar as similaridades entre os respondentes da pesquisa (Fávero, Belfiore, Silva; \& Chan, 2009).

A variável utilizada foi a aquisição da bicicleta, uma vez que ao serem questionados se possuíam bicicleta, $58 \%$ dos participantes responderam que sim, enquanto $42 \%$ dos declararam não possuir bicicleta, quando necessitam utilizam o sistema Bicicletar.

Foram formados dois grupos, com as variáveis: gênero, renda, idade, escolaridade e motivo pelo qual utiliza a bicicleta (atividade física, lazer e meio de transporte). Verificou-se que há maior concentração de casos no cluster 1, com 77 casos, em comparação com o cluster 2, com 55 participantes.

Identificou-se, na Tabela 1, o gênero dos respondentes que constituíram os clusters. Embora haja maior participação do gênero feminino em ambos os clusters, verificou-se que há uma distribuição bem equilibrada entre os gêneros dos usuários, convergindo com os achados da pesquisa de Diógenes, Araújo, Tassigny e Bizarria (2017), em que os autores relatam avanços na discussão sobre a utilização das bicicletas, que gerou a migração do perfil masculino para um perfil balanceado entre homens e mulheres.

Tabela 1

Distribuição de cluster por gênero

\begin{tabular}{cccc}
\hline & Feminino & Masculino & Total \\
\hline Cluster 1 & 40 & 37 & 77 \\
Cluster 2 & 29 & 26 & 55 \\
& Total & & 132 \\
\hline
\end{tabular}

Fonte: Dados da pesquisa (2020).

A Tabela 2 expõe a distribuição dos grupos em relação à faixa etária. No cluster 1 , composto por 77 respondentes, cujas idades possuem distribuição em todas as faixas etária, havendo predomínio de adultos (30 a 59 anos). Por sua vez, o cluster 2 tem a participação de 55 casos, havendo maior participação do público jovem (15 a 29 anos). Infere-se que o perfil dos clusters indica que o uso da bicicleta por um público com perfil jovem, proporcionando maior conscientização dos respondentes que se encontram em processo de construção identitária e social, em consonância com o evidenciado por Diógenes et al. (2017).

Tabela 2

\section{Distribuição de cluster por faixa etária}

\begin{tabular}{lcccccccccc}
\hline & 15 a 19 & 20 a 24 & 25 a 29 & 30 a 34 & 35 a 39 & 40 a 44 & 45 a 49 & 50 a 54 & 60 a 64 & Total \\
\hline Cluster 1 & 4 & 20 & 11 & 13 & 11 & 5 & 10 & 2 & 1 & 77 \\
Cluster 2 & 5 & 16 & 18 & 7 & 6 & 2 & 1 & 0 & 0 & 55
\end{tabular}


Total

Fonte: Dados da pesquisa (2020).

A distribuição dos grupos quanto à renda é evidenciada na Tabela 3. Verifica-se no cluster 1 a concentração de respondentes que auferem renda entre $\mathrm{R} \$ 1.000,00$ e $\mathrm{R} \$ 5.000,00$. Há uma distribuição equilibrada em relação à faixa de renda superior a $\mathrm{R} \$ 10.000,00$ nos dois clusters. Em relação ao cluster 2, há predomínio dos participantes sem renda.

Tabela 3

Distribuição de cluster por renda

\begin{tabular}{|c|c|c|c|c|c|c|}
\hline & Sem renda & $\begin{array}{c}\text { Até } \\
\mathrm{R} \$ 1.000,00\end{array}$ & $\begin{array}{c}\text { Entre } R \$ 1.000,00 \mathrm{e} \\
\mathrm{R} \$ 5.000,00\end{array}$ & $\begin{array}{l}\text { Entre } R \$ 5.000,00 \mathrm{e} \\
\mathrm{R} \$ 10.000,00\end{array}$ & $\begin{array}{c}\text { Acima de } \\
\mathrm{R} \$ 10.000,00\end{array}$ & Total \\
\hline Cluster 1 & 11 & 19 & 32 & 12 & 3 & 77 \\
\hline Cluster 2 & 14 & 12 & 19 & 8 & 2 & 55 \\
\hline Total & & & & & & 132 \\
\hline
\end{tabular}

Fonte: Dados da pesquisa (2020).

No que concerne à escolaridade, os grupos, representados na tabela 4, observou-se que no cluster 1 há respondentes de todos os níveis de escolaridade, com concentração nos que possuem ensino superior completo e em andamento. Há um equilíbrio, nos dois clusters, de participantes com pós-graduação. O nível de escolaridade dos respondentes pode indicar maior disseminação do conhecimento propiciando uma compreensão sobre a problemática urbana e a construção de novos valores que estimulem à adesão a novos estilos de vida, conforme exposto por Diógenes et al. (2017).

Tabela 4

Distribuição de cluster por escolaridade

\begin{tabular}{lccccccc}
\hline & $\begin{array}{c}\text { Fundamental } \\
\text { Completo }\end{array}$ & $\begin{array}{c}\text { Médio } \\
\text { Incompleto }\end{array}$ & $\begin{array}{c}\text { Médio } \\
\text { Completo }\end{array}$ & $\begin{array}{c}\text { Superior em } \\
\text { Andamento }\end{array}$ & $\begin{array}{c}\text { Superior } \\
\text { Completo }\end{array}$ & $\begin{array}{c}\text { Pós- } \\
\text { graduação }\end{array}$ & Total \\
\hline Cluster 1 & 1 & 1 & 2 & 28 & 24 & 21 & 77 \\
Cluster 2 & 0 & 0 & 3 & 18 & 13 & 21 & 55 \\
Total & & & & & & & 132 \\
\hline
\end{tabular}

Fonte: Dados da pesquisa (2020).

Segundo Rosemberg (2015), a Associação Brasileira dos Fabricantes de Motocicletas, Ciclomotores, Motonetas, Bicicletas e Similares (ABRACICLO) divulgou uma nova segmentação no mercado de bicicletas, classificando-a sob cinco categorias: mobilidade urbana, recreação e lazer, esporte e competição e uso infantil e básica para transporte. Tal classificação busca alterar a imagem da bicicleta, que era vista como bem inferior (conforme a renda cresce, seu consumo cai) associada às pessoas de baixa renda.

Assim, buscou-se identificar os motivos pelos quais os respondentes utilizam a bicicleta, conforme Tabela 5. Verificou-se que no cluster 1 há maior concentração de 
participantes que utilizam a bicicleta para realização de atividade física e como instrumento de lazer e meio de transporte. Enquanto no cluster 2 a maior concentração é daqueles usuários que a utilizam como instrumento de lazer. Tal achado se alinha com o exposto por Diógenes et al. (2017), segundo o qual o fortalecimento na utilização de bicicletas deve-se à sua disseminação como alternativa viável de transporte e ao contexto cultural urbano em que são disponibilizados novos espaços que estimulam o uso da bicicleta em atividades de lazer.

\section{Tabela 5}

\section{Distribuição de cluster por utilização da bicicleta}

\begin{tabular}{lcccccccc}
\hline & $\begin{array}{c}\text { Atividade } \\
\text { Física }\end{array}$ & Lazer & $\begin{array}{c}\text { Meio de } \\
\text { Transporte }\end{array}$ & $\begin{array}{c}\text { Atividade } \\
\text { Física } \\
\text { Lazer }\end{array}$ & $\begin{array}{c}\text { Atividade } \\
\text { Física e Meio } \\
\text { de Transporte }\end{array}$ & $\begin{array}{c}\text { Meio de } \\
\text { Transporte } \\
\text { e Lazer }\end{array}$ & $\begin{array}{c}\text { Atividade Física, } \\
\text { Lazer e Meio de } \\
\text { Transporte }\end{array}$ & Total \\
\hline Cluster 1 & 8 & 6 & 5 & 25 & 5 & 9 & 19 & 77 \\
Cluster 2 & 3 & 14 & 3 & 12 & 5 & 9 & 9 & 55 \\
Total & & & & & & & & 132 \\
\hline
\end{tabular}

Fonte: Dados da pesquisa (2020).

Por meio da distribuição das variáveis elencadas nas tabelas 1, 2, 3, 4 e 5 foi possível depreender o perfil de dois clusters. O primeiro cluster é formado por respondentes que possuem bicicleta. Predominam os respondentes do gênero feminino, sendo formado por pessoas menos jovens em relação ao cluster 2. Além disso, há uma maior distribuição de renda e representação em todos os níveis de formação. Os respondentes utilizam a bicicleta para realização de atividade física, lazer e meio de transporte.

Já no segundo cluster, também prevalece o gênero feminino. Em relação à faixa etária, este grupo é formado por pessoas mais jovens. Tal fato é evidenciado por Providelo e Sanches (2010) ao constatarem que os jovens representam a parcela da população que mais utiliza bicicletas. Ademais, os respondentes auferem baixos rendimentos e, também, possuem formação em nível superior (completo e incompleto e pós-graduação). Neste cluster, os participantes utilizam a bicicleta para o lazer. Devido a este perfil, infere-se a presença de estudantes como integrantes do cluster 2, que por não possuírem bicicleta, utilizam o sistema Bicicletar, corroborando os achados da pesquisa de Rechene e Silva (2020), ou ainda podem locar a bicicleta a fim de participar de passeios noturnos, bem disseminados na capital cearense.

Uma vez que avanços na discussão sobre a utilização da bicicleta ocasionou mudanças do perfil dos usuários (de um público masculino para um perfil equilibrado entre os gêneros) nos quais estes precisam se convencer dos benefícios oriundos da utilização da bicicleta (Forward, 2014; Diógenes et al., 2017), com base nos dados apresentados pressupõe-se uma 
evolução na forma de uso, posto que os respondentes a percebem como meio de transporte e instrumento para estimular saúde e lazer.

Os achados evidenciam um público que utiliza a bicicleta de forma a aproveitar o espaço urbano, intermediado pelas políticas de apoio ao transporte cicloviário e o sistema de bicicletas compartilhadas que estimulam o cidadão a utilizar um modo de transporte sustentável (Castro et al., 2013) e contribuem para a construção e disseminação de novos valores que norteiam as ações dos indivíduos (Iwai, 2016).

\subsection{Setores movimentados pela economia da bicicleta}

Segundo Weigand (2008), a bicicleta e as atividades relacionadas à indústria, vendas e serviços constituem uma força econômica significativa e fornecem fonte de renda e empregos. No entanto, não é comum a mensuração do impacto econômico provocado pelo ciclismo. Os usuários de bicicleta afetam a economia local por meio do dinheiro gasto em deslocamentos, ao obter produtos e serviços (Pereira \& Silva, 2018).

Assim, buscou-se investigar quais segmentos de mercados são os mais afetados pela economia da bicicleta, em categorias de destino que têm potencial para negócios adicionais e repetidos devido a níveis de acessibilidade (Schoner, Harrison, \& Wang, 2012). Os respondentes foram questionados se já utilizaram a bicicleta para chegar a determinado segmento de negócio, e em caso afirmativo, os mesmos informavam o quanto havia gasto no(s) estabelecimento(s).

A Tabela 6 proporcionou informações sobre a economia local estimulada pela utilização da bicicleta. Verificaram-se que os gastos ainda são incipientes, pois grande parte dos respondentes não utiliza a bicicleta para chegar a determinado negócio ou não soube informar o valor gasto em sua viagem e quando realizam compras, os respondentes dispendem modesta quantia, que podem não ser percebidas pelos comerciantes. Em relação ao segmento mantimentos e compras, a maior movimentação econômica é nos supermercados com 25\%. Já no ramo de alimentação, encontram-se as sorveterias com 19\%, enquanto no segmento lazer e cultura o maior dispêndio é realizado nas praias (28\%) e nos serviços destacam-se os salões de beleza com 12\%. Tais achados convergem com o exposto por $\mathrm{Si}$, Chen, Liu e Yan (2020), ao relatarem que os usuários de bicicletas são consumidores que movimentam segmentos econômicos de baixo custo e que a utilizam em decorrência da necessidade de deslocamentos de curta distância.

Tabela 6

Revista Gestão e Secretariado (GeSec), São Paulo, SP, 12(1), jan./abr., 2021, p. 79-105. 


\section{Movimentação econômica por segmento (Em \%)}

\begin{tabular}{ccccccc}
\hline \multirow{2}{*}{ Segmento } & $\begin{array}{c}\text { Você usa bicicleta } \\
\text { para chegar a (o) }\end{array}$ & $\begin{array}{c}\text { Menos de R\$ } \\
10,00\end{array}$ & $\begin{array}{c}\text { Entre R } \$ 10,00 \\
\text { e R \$ 50,00 }\end{array}$ & $\begin{array}{c}\text { Acima de } \\
\text { R \$ 50,00 }\end{array}$ & $\begin{array}{c}\text { Não } \\
\text { utiliza }\end{array}$ & Total \\
\hline \multirow{3}{*}{$\begin{array}{c}\text { Mantimentos e } \\
\text { Compras }\end{array}$} & Supermercado & 5 & 15 & 5 & 75 & 100 \\
& Padaria & 9 & 11 & 0 & 80 & 100 \\
& Farmácia & 4 & 13 & 2 & 81 & 100 \\
& Loja de bens de & & & & & \\
& consumo & 3 & 5 & 7 & 85 & 100 \\
& Sorveteria & 8 & 10 & 1 & 81 & 100 \\
Alimentação & Cafeteria & 3 & 11 & 1 & 85 & 100 \\
& Lanchonete & 2 & 8 & 1 & 89 & 100 \\
& Restaurante & 1 & 6 & 2 & 91 & 100 \\
\multirow{5}{*}{ Lazer e Cultura } & Praia & 22 & 6 & 0 & 72 & 100 \\
& Parque & 18 & 7 & 0 & 75 & 100 \\
& Cinema & 3 & 7 & 1 & 89 & 100 \\
& Bar & 0 & 9 & 2 & 89 & 100 \\
& Salão & 2 & 8 & 2 & 88 & 100 \\
& Academia & 4 & 3 & 0 & 93 & 100 \\
& Banco & 3 & 0 & 3 & 94 & 100 \\
& Médico & 1 & 1 & 3 & 95 & 100 \\
\hline
\end{tabular}

Fonte: Dados da pesquisa (2020).

Infere-se que a movimentação é limitada, considerando as estações de bicicleta compartilhada e a infraestrutura cicloviária da cidade, contrapondo o exposto por Schoner et al. (2012), ao considerarem que melhorias na acessibilidade implicam no crescimento do potencial de mudanças na atividade econômica local.

Uma vez que 58\% dos respondentes possuem bicicleta, investigou-se, também, a movimentação econômica promovida pela aquisição de acessórios relacionados à atividade de ciclismo.

\section{Tabela 7}

\section{Despesas com acessórios para bicicleta (Em \%)}

\begin{tabular}{ccccccc}
\hline Quanto você gastou com & $\begin{array}{c}\text { Menos de } \\
\mathrm{R} \$ 50,00\end{array}$ & $\begin{array}{c}\text { Entre } \\
\mathrm{R} \$ 50,00 \mathrm{e} \\
\mathrm{R} \$ 100,00\end{array}$ & $\begin{array}{c}\text { Entre } \\
\mathrm{R} \$ 100,00 \mathrm{e}\end{array}$ & $\begin{array}{c}\text { Acima de } \\
\mathrm{R} \$ 300,00\end{array}$ & Não tem & Total \\
\hline Lanterna & 23 & 10 & 5 & 2 & 60 & 100 \\
Capacete & 7 & 17 & 13 & 1 & 62 & 100 \\
Blusa para ciclismo & 12 & 14 & 4 & 2 & 68 & 100 \\
Luva & 19 & 6 & 2 & 1 & 72 & 100 \\
Bermuda de ciclismo & 6 & 13 & 5 & 1 & 75 & 100 \\
Transbike & 4 & 6 & 8 & 4 & 78 & 100 \\
Buzina & 17 & 2 & 2 & 0 & 79 & 100 \\
Sapatilha & 1 & 4 & 1 & 5 & 89 & 100 \\
\hline
\end{tabular}

Fonte: Dados da pesquisa (2020). 
Conforme Tabela 7, verificou-se que $89 \%$ dos respondentes não possuem o item sapatilha, enquanto os demais itens: lanterna (40\%), capacete $(38 \%)$, blusa para ciclismo (32\%), luva (28\%), bermuda para ciclismo (25\%), transbike (22\%) e buzina $(21 \%)$ foram adquiridos pelos respondentes em maior proporção que os itens da Tabela 6. Isto pode vir ao encontro do proposto por Si et al. (2020) sobre a movimentação de um nicho de mercado específico, ao se pressupor que incremento nas vendas de tais itens devem ser percebido pelos empresários do ramo de venda de peças e serviços de bicicletas, considerando que é um segmento de mercado de transporte urbano que se torna indispensável para os seus usuários.

\subsection{Análise das entrevistas}

Por meio dos relatos dos entrevistados, do segmento de vendas e serviços de bicicletas, foi possível identificar o aumento do fluxo de ciclistas nos últimos dois anos, quando as ações de incentivo ao uso de bicicletas passaram efetivamente a ser implementadas pela Prefeitura de Fortaleza. Tais relatos estão de acordo com o exposto por Ricieri, Fontenele e Silva Junior (2017), ao argumentarem que a implantação de infraestrutura e políticas de incentivo, em alguns municípios brasileiros, tem estimulado o uso da bicicleta como modo de transporte, uma vez que no Brasil, a bicicleta é percebida como instrumento de esporte e lazer.

Além de perceberem tal aumento no fluxo, os comerciantes conseguem inferir a contribuição das políticas públicas neste fenômeno, como afirma o entrevistado E4: “[...] Com certeza teve aumento, principalmente com as ciclofaixas. Com as redes sociais todo mundo ficou sabendo, se interessou pelo esporte. Aumentou com certeza, aumento considerável [...]”.

O entrevistado E8 também confirma a contribuição das ciclofaixas no incremento de fluxo de clientes em seu negócio "[...] sim, teve um aumento significativo, de uns 50 por cento. A instalação de ciclovias na cidade facilitou para algumas pessoas que tinham vontade, incentivou. E a própria ciclofaixa de lazer também facilitou”.

Estes relatos corroboram o resultado da pesquisa de Providelo e Sanches (2010) sobre percepções de indivíduos acerca do ciclismo como modo de transporte, onde a infraestrutura específica para bicicletas (ciclovia e ciclofaixas) foi apontada como um dos três principais fatores para uma atitude positiva em relação ao deslocamento por bicicletas.

Em contrapartida, os comerciantes de outros segmentos, além da venda e de serviços de bicicleta, não apresentaram opiniões otimistas quanto ao aumento do fluxo de clientes em suas lojas nos últimos anos. Dois deles salientaram que percebem um maior número de 
usuários de bicicletas nas imediações, mas que isso não reverberou no fluxo da loja ou no incremento de vendas. O proprietário do bar que funciona há apenas poucos metros de uma ciclovia e de uma estação do Bicicletar ressaltou: “[...] eu consigo observar que existe um fluxo bem maior de transeuntes andando nas bicicletas do Bicicletar, mas como cliente para o bar, não (E3)." O funcionário de um restaurante/churrascaria localizado em frente a concentração de um passeio ciclístico noturno complementou: “[...] aumentou mais o movimento, aumentou muito. Já o faturamento não, porque geralmente se eles vêm só para tomar água, essas coisas. Não comem nem consomem bebida, só toma água, então é quase a mesma coisa (E1).”

Tais relatam corroboram os dados evidenciados na Tabela 6, em que se verificou uma baixa movimentação econômica por segmento, ratificando a visão de Si et al. (2020), em que os usuários de bicicletas estimulam segmentos de mercado de baixo custo, e pela utilização de bicicleta como instrumento de esporte e de lazer (Ricieri, Fontenele; \& Silva Junior, 2017).

Importante salientar que mesmo percebendo aumento no fluxo de ciclistas, nenhum dos dez estabelecimentos visitados oferece bicicletário como estratégia de aproximação e fidelização de clientes, uma vez que o bicicletário e os paraciclos conferem maior visibilidade aos estabelecimentos comerciais (Ricieri et al., 2017). Já os entrevistados E2, E7 e E9 foram taxativos ao afirmarem que não registraram aumento no fluxo de clientes ciclistas, ao mesmo tempo em que notaram um decréscimo na quantidade geral de clientes após a implantação das ciclovias próximas aos estabelecimentos, o que dificultaria o acesso de pessoas com veículos motorizados:

[...] o fluxo de cliente caiu por conta do estacionamento porque depois que fizeram essa ciclovia, os taxistas fizeram um abaixo assinado e mudaram para esse lado. Os clientes colocavam os carros aqui e, por conta disso, não colocam mais, daí as vendas caíram e as reclamações foram uma atrás da outra. A vizinhança todinha tentou um abaixo assinado para poder tirar a ciclovia daqui, e até agora não vi nenhum progresso em relação a isso (E2).

O entrevistado E9 concorda e atribui às ciclovias os problemas de acesso de seus clientes ao estabelecimento "[...] diminuiu um pouco, porque aqui antes era estacionamento, os clientes estacionavam aqui e tinham acesso mais rápido e fácil e agora não. Eu já escutei de cliente que vem e não consegue estacionar e por isso passa direto (E9).”

Já o sujeito E7, do ramo de restaurantes, afirma que a ciclofaixa de lazer também teve um impacto negativo sob o seu negócio: “[...] A ciclofaixa não mudou nada, ao contrário, fez foi prejudicar. Porque além da ciclofaixa tem a faixa do ônibus e aí ficou muito congestionado. Fez for diminuir mais o fluxo por aqui." 
Mesmo concordando que o fluxo de clientes regrediu nos últimos anos nenhum dos estabelecimentos pesquisado oferece ações de fidelização ou ofertas especiais para atrair clientes que trafegam nas ciclovias ou ciclofaixas próximas aos locais: “[...] nunca pensei nisso. Essas ideias para ciclistas eu nunca percebi muito não, é mais os de moto, mas ciclistas mesmo eu nunca tive esse interesse (E7)."

Um dos entrevistados afirmou que já tentou instalar um bicicletário e procurou as autoridades responsáveis, mas desistiu em função da burocracia que, de acordo com ele, é demasiada:

Eu tive uma iniciativa há uns sessenta dias atrás de colocar aqui um apoio para as bicicletas, aquele estacionamento para bicicletas. Fui até a AMC, mas a burocracia é tamanha porque eu vou tomar parte da rua, que eu tenho que pedir autorização dos vizinhos, fazer um projeto etc. Como não tenho um fluxo de ciclista muito grande que possa melhorar a minha venda achei por bem parar. Queria agregar algo a minha venda, mas como foi muita dificuldade e eu vendo que meu cliente não exigia isso, preferi parar (E6).

A partir dos trechos apresentados, infere-se que a infraestrutura disponível para utilização da bicicleta, interferiu em alguns negócios locais, pois alguns estabelecimentos perderam espaço que utilizavam como estacionamento aos clientes com automóveis em função das ciclofaixas. Ressalta-se que a busca pela potencialização da utilização de bicicleta como meio alternativo de transporte deve ser acompanhada por campanhas publicitárias que enfatizem a finalidade do investimento cicloviário de forma a motivar os cidadãos a realizarem viagens diárias (Ricieri et al., 2017) de forma a gerar um cenário em que se vincule o planejamento urbano, a percepção dos usuários de bicicletas e o segmentos comerciais locais, atendendo, assim, aos interesses da população.

O apoio ou patrocínio de eventos ligados ao ciclismo foi a única ação de marketing citada por dois dos entrevistados, um do segmento de farmácias e um supermercadista: “[...] A gente sempre faz um passeio ciclístico no Montese, todo ano, no mês de outubro (E6) "e “[...] só uma vez por ano que fazemos o Pedala "Nome da Farmácia", que é um passeio ciclístico onde a gente divulga a empresa (E5).”

Tais ações promovidas pelos entrevistados podem auxiliar na construção de uma cultura local da utilização da bicicleta em espaços urbanos conforme propõem Rechia, Tschoke, Machado e Joukoski (2016), além de serem ações estratégicas de posicionamento diferenciado no mercado (Mourad \& Serralvo, 2018).

Já ao serem abordados sobre em que segmento o faturamento teve maior crescimento nos últimos dois anos, os entrevistados do ramo de vendas e serviços de bicicleta, parecem concordar que há certo equilíbrio como revela um dos depoimentos: “[...] como os clientes 
compram as bikes com a gente o serviço de manutenção acaba aumentando em consonância, um complementa o outro, o aumento é progressivo (E4)". O acréscimo das vendas de tal segmento por ser explicado pela potencialização da utilização da bicicleta implicando na movimentação dos indivíduos na cidade de Fortaleza, conforme exposto por Diógenes et al. (2017).

\section{Conclusão}

O estudo buscou delinear o perfil dos sujeitos usuários de bicicleta, investigar os segmentos de mercado fomentados pela economia da bicicleta e identificar a percepção dos empresários em relação aos usuários desse modal como clientes, na cidade de Fortaleza (CE).

Constataram-se avanços na forma de uso e da imagem da bicicleta, utilizada, em sua maioria por jovens do gênero feminino e com formação educacional em nível superior que a percebem como meio de transporte e instrumento para estimular saúde e lazer.

Em relação à movimentação econômica proporcionada pelos deslocamentos realizados com a bicicleta, verificou-se que os gastos ainda são incipientes, pois grande parte dos respondentes não utiliza a bicicleta para chegar a determinado negócio ou não soube informar o valor gasto em sua viagem. Todavia, quando realizam compras, dispendem modesta quantia, acarretando uma inexpressiva movimentação econômica local por parte dos respondentes. O segmento de mercado mais fomentado pelos usuários é do ramo de ciclismo, pois identificaram-se aquisições em maiores proporções que os demais segmentos.

Quanto à percepção dos empresários, apenas os proprietários de estabelecimentos especializados em venda e serviços de bicicletas perceberam incrementos nos seus negócios, devido à expansão da infraestrutura específica para bicicletas e à cultura de mobilidade urbana trazida por ela (Diógenes et al., 2017), uma vez que os sujeitos-usuários adquirem acessórios relacionados à atividade de ciclismo ou buscam serviços de manutenção e/ou reparo.

Entende-se que a concentração de pessoas e de negócios interfere na economia urbana e contribue para o desenvolvimento local. Diante da problemática ambiental e da mobilidade urbana, deveria se promover a utilização da bicicleta como meio de transporte sustentável e de fomento a economia local, uma vez que os resultados demonstraram os deslocamentos com bicicleta movimentam a economia local de forma incipiente, e cabe, também, aos empresários desenvolverem estratégias que atraiam esses consumidores e incrementem as vendas.

Em geral, muitos estudos têm contribuído no entendimento sobre o perfil de usuários de bicicleta, mas a maioria tem se baseado em experiências de outros países, principalmente 
europeus, onde o ciclismo é historicamente mais praticado pela população. Os estudos existentes ainda diagnosticam, em geral, o perfil do usuário e os fatores incentivadores ou restritivos ao seu uso, não dando tanta importância a influência do uso da bicicleta na economia local.

No sentido de contribuir e ampliar o conhecimento sobre o perfil de utilização da bicicleta e os impactos econômicos, o estudo concentrou na perspectiva de dois agentes mais atuantes no setor: os usuários e as empresas. Sob a perspectiva acadêmica, social e empresarial, consideram-se os resultados relevantes, uma vez que se buscou apresentar a bicicleta como instrumento de fomento a economia local, e não apenas como meio de transporte sustentável.

Ressalta-se que não cabe generalização dos achados da pesquisa, uma vez que se limitou a uma realidade específica. Entretanto, sugere-se que sejam realizadas pesquisas futuras que examinem o impacto econômico do ciclismo, relacionando-o às formas de produção, vendas, emprego, renda e receitas tributárias, e do cicloturismo.

\section{Referências}

Andion, C. (2003). Análise de redes e desenvolvimento local sustentável. Revista de Administração Pública - RAP, 37 (5), 1033 - 1054.

Araújo, M. R. M; Sousa, D.A.;Oliveira, J. M.; Jesus, M. S.; Sá, N. R.; Santos, P. A. C., \& Lima, T. C.(2009). Andar de bicicleta: contribuições de um estudo psicológico sobre mobilidade. Temas em Psicologia. 17 (2), 481-495.

Bowles, B.; Fleming, K., Fuller, K., Lankford, J., \& Printz, J. (2011). Economic and health benefits of bicycling in Iowa. (University of Northern Iowa). Retrieved from http://www.peoplepoweredmovement.org/site/images/uploads/Economic_and_Health_Be nefits_of_Bicycling_in_Iowa.pdf

Castro, C. M. S. E., Barbosa, H. M., \& Oliveira, L. K. (2013). Análise do potencial de integração da bicicleta com o transporte coletivo em Belo Horizonte. Journal of. Transporte Literature. 7(2), 146-170.

Coelho, E.M. Jr., Vilas, G.T.; Silva, K. K. P. \& Pereira, R. V. (2015) Impactos positivos das implementações de ciclovias, ciclofaixas e faixas compartilhadas no município de São Paulo. Anais do Encontro Internacional sobre Gestão Empresarial e Meio Ambiente (ENGEMA), São Paulo, SP, Brasil, 18. 
Collis, J., \& Hussey, R. (2009). Pesquisa em administração: Um guia prático para alunos de graduação e pós-graduação. (2a ed.). Porto Alegre: Bookman.

Diniz, C. C., Santos, F. S., Crocco, M. (2006). Conhecimento, inovação e desenvolvimento regional/local In: Diniz, C. C., \& Crocco, M. (Orgs.). Economia regional e urbana: contribuições teóricas recentes. Belo Horizonte, MG: Editora UFMG.

Diógenes, K. C. A., Araújo, M. A. F., Tassigny, M. M., \& Bizarria, F. P. A. (2017). Perspectivas de mobilidade urbana sustentável e a adesão ao modo cicloviário. Revista de Gestão Social e Ambiental, 11(1), 21-37.

Edra, F. P. M., Costa, M. L., \& Fernandes, T. T. (2015). Cicloturismo em Niterói: potencialidade a partir do Rio de Janeiro. Caderno Virtual de Turismo, 15(3), 331-345.

European Cyclists' Federation (2015, 22 de dezembro). Cycling works and job in the cycling economy. Brussels, Belgium: author. Retrieved from https:/ecf.com/groups/cyclingworks-jobs-and-job-creation-cycling-economy

Fávero, L. P., Belfiore, P.; Silva, F.L. \& Chan, B. L. (2009). Análise de dados: Modelagem multivariada para tomada de decisões. Rio de Janeiro, RJ: Elsevier.

Ferrarini, A. V. (2012). Desenvolvimento local integrado e sustentável: uma metodologia para políticas e programas de superação da pobreza. Interações, 13 (2), 233-241.

Forward, S.E. (2014). Exploring people's willingness to bike using a combination of the theory of planned behavioural and the transtheoretical model. Revue Européenne de Psychologie Appliquée, 64, 151-159.

Franco, C.M.A. (2011). Incentivos e empecilhos para a inclusão da bicicleta entre universitários. Dissertação de mestrado, Universidade Federal do Paraná, Curitiba, PR, Brasil.

Gomes, R. (2012). Análise e interpretação de dados de pesquisa qualitativa. In: Minayo, M. C. S., Deslandes, S. F \& Gomes, R. (Orgs.). Pesquisa social: teoria, método e criatividade. (32a ed.). Petrópolis: Vozes.

Gray, D. E. (2012). Pesquisa no mundo real. (2a ed.). Porto Alegre, RS: Penso.

Instituto de Energia e Meio Ambiente (2010). A bicicleta e as cidades: como inserir a bicicleta na política de mobilidade urbana. Renato Boareto (Org.). (2a ed.) São Paulo, SP: author. Disponível em: http://www.energiaeambiente.org.br/wpcontent/uploads/2015/09/A-bicicleta-e-as-cidades.pdf

Instituto de Planejamento de Fortaleza -Iplanfor. (2015). Plano de Mobilidade de Fortaleza (PlanMob). Fortaleza, CE: author. Disponível em 
http://fortaleza2040.fortaleza.ce.gov.br/site/assets/files/publications/fortaleza2040_plano _de_mobilidade_urbana_17-08-2015.pdf

Iwai, T. (2016). Orientação de valor social, sistema de valores e comportamento cooperativo: um estudo experimental. Revista de Administração Mackenzie, 17(1), 82-111.

Martins, R. D. \& Caldas, E.L. (2009). Visões do desenvolvimento local: uma análise comparada de experiências brasileiras. Interações, 10 (2), 207-218.

Martins, R. D., Vaz, J.C. \& Caldas, E. L. (2010). A gestão do desenvolvimento local no Brasil: (des)articulação de atores, instrumento e território. Revista de Administração Pública - RAP, 44 (3), 559-590.

Mason, J.; Fulton, L. \& Mcdonald, Z. (2015). A global high shift cycling scenario: the potential for dramatically increasing bicycle and e-bike use in cities around the world. (Institute for Transportations \& Development Policy e University of California, Davis). Retrieved from https://www.itdp.org/wp-content/uploads/2015/11/A-Global-High-ShiftCycling-Scenario_Nov-2015.pdf

Milheiro, V. (2016). Bicicleta e qualidade de vida nas cidades. Revista da UIIPS, 4(1), 200215.

Ministério das Cidades (2007). Programa brasileiro de mobilidade por bicicleta - Bicicleta Brasil: Caderno de referência para elaboração de plano de mobilidade por bicicleta nas cidades. Brasília, DF: Secretaria Nacional de Transporte e da Mobilidade Urbana. Disponível em: https:// www.cidades.gov.br/images/stories/ArquivosSEMOB/Biblioteca/LivroBicicletaBrasil.pd $\mathrm{f}$

Monteiro, J. P. R., \& Monteiro, M.S. L. (2006). Hortas comunitárias de Teresina: agricultura urbana e perspectiva de desenvolvimento local. Revista Iberoamericana de Economia Ecológica, 5, 47-60.

Mota, J. C.; \& Sá, F. M. (2013). A valorização económica da bicicleta em Portugal. Transportes em Revista, pp.46-52 Disponível em http://ordenaracidade.pt/sitejcarvalho/assets/files/2052/tr_130_valoriza_o_da_bicicleta.pdf

Mourad, A. I., \& Serralvo, F. A. (2018). Estudo sobre a influência do posicionamento de marca no desempenho competitivo das organizações. Future Studies Research Journal: Trends and Strategies, 10(3), 427-449.

Muls, L. M. (2008). Desenvolvimento local, espaço e território: o conceito de capital social e a importância da formação de redes entre organismos e instituições locais. Economia, 9 (1), 1-21. 
Németh, J. (2009). Defining a public: the management of privately owned public space. Urban Studies, 46 (11), 2463-2490.

Olekszechen, N.; Battiston, M.; \& Kuhnen, A. (2016). Uso da bicicleta como meio de transporte nos estudos pessoa-ambiente. Desenvolvimento e Meio ambiente, 36, 355-369.

O Povo Online (2015, 9 de dezembro). Bicicletar - Fortaleza lidera ranking de bicicletas compartilhadas no Brasil. Fortaleza, CE: author. Disponível em http://www20.opovo.com.br/app/fortaleza/2015/09/10/noticiafortaleza,3502212/fortaleza -lidera-utilizacao-de-bicicletas-compartilhadas-no-brasil.shtml

O Povo Online (2016, 01 de junho). Seis novas estações do Bicicletar serão entregues nesta quinta-feira. Fortaleza, CE: author. Disponível em http://www.opovo.com.br/app/fortaleza/2016/06/01/noticiafortaleza,3619251/seis-novasestacoes-do-bicicletar-serao-entregues-nesta-quinta.shtml

Passador, C. S., \& Passador, J. L. (2010). Apontamentos sobre as políticas públicas de combate à seca no Brasil: cisternas e cidadania? Cadernos Gestão Pública e Cidadania, $15(6), 65-86$.

Passafaro, P., Rimano, A., Piccini, M. P., Metastasio, R., Gambardella,V., Gullace, G., \& Lettieri, C.(2014) .The bicycle and the city: Desires and emotions versus attitudes, habits and norms. Journal of Environmental Psychology, 38, 76 - 83.

Patricio, L.C.B., \& Kruszielski, L. (2016). Dia de bicicleta ao trabalho: uma potencial ferramenta para planejamento e promoção da mobilidade sustentável. Revista de Gestão Ambiental e Sustentabilidade - GeAS, 5(3), 135-151.

Pereira, C.H.T., \& Silva, M.E. (2018). A economia compartilhada como movimento de transição. Revista de Gestão Ambiental e Sustentabilidade - GeAS, 7(3), 451-468.

Providelo, J. K., \& Sanches, S. P. (2010). Percepções de indivíduos acerca do uso da bicicleta como modo de transporte. Transportes, 18, 53-61.

Quigley, J. M. (2008). Urban economics: the new palgrave dictionary of economics (2nd ed.). [Adobe digital editions version]. DOI:10.1057/9780230226203.1770

Rechene, S. T., \& Silva, M. E. (2020). Vamos pedalar? A sustentabilidade na percepção de usuários de bicicletas compartilhadas. Revista Metropolitana de Sustentabilidade, 10 (2).

Rechia, S., Tschoke, A., Machado, G. C., \& Joukoski, S. (2016). O lazer sobre duas rodas: uma questão de espaço, tempo e ação em Curitiba-PR. Pensar a Prática, 19(3), 568-578.

Richardson, R. J. (2012). Pesquisa social: Métodos e técnicas. (3a ed.). São Paulo, SP: Atlas. 
Ricieri, M. G., Fontenele, H. B., \& da Silva Junior, C. A. P. (2017). Percepção de cidadãos de uma cidade de médio porte em relação ao uso da bicicleta como modo de transporte. REEC-Revista Eletrônica de Engenharia Civil, 13(1), 283-296.

Roma, C. M. (2016). Circuito inferior da economia urbana e cidades locais-híbridas. Mercator-Revista de Geografia da UFC, 15(2), 23-36.

Rosemberg Associados. (2015). O uso de bicicletas no Brasil: qual o melhor modelo de incentivo? Associação Brasileira dos Fabricantes de motocicletas, ciclomotores, motonetas, bicicletas e similares (ABRACICLO). Disponível em http://www.abraciclo.com.br/downloads/34-seguranca/968-estudo-rosenberg.

Santos, C. C., \& Souza, S. L. (2014, Agosto). A pobreza urbana e os dois circuitos da economia urbana: reflexões teóricas. Anais do Congresso Brasileiro de Geógrafos $(C B G)$. Vitória, ES, Brasil, 7.

Santos, M. (2008). Espaço dividido: os dois circuitos da economia urbana dos países subdesenvolvidos. (2a ed.). São Paulo, SP: Editora da Universidade de São Paulo.

Sausen, J. O., Patias, I. A., \& Allebrandt, S.L. (2011). Desenvolvimento local e estratégia de pequenos empreendimentos agroindustriais - a lógica da cooperação e do associativismo: o Pacto Fonte Nova. Cadernos Ebape.BR, 9 (3), 870-894.

Schoner, J. E., Harrison, R. A., \& Wang, X. (2012). Sharing to grow: economic activity associated with nice ride bike share stations. (Technical report, University of Minnesota). Retrieved from http://conservancy.umn.edu/handle/11299/135470

Si, S., Chen, H., Liu, W., \& Yan, Y. (2020). Disruptive innovation, business model and sharing economy: the bike-sharing cases in China. Management Decision, Ahead-ofprint.

Silveira, M. O., \& Maia, M. L. A. (2015). Variáveis que influenciam no uso da bicicleta e as crenças da teoria do comportamento planejado. Transportes, 23(1), 24-36.

Silveira, M. O., \& Maia, M. L. A. (2013, Novembro). Comportamento e uso da bicicleta. Anais do Congresso de Pesquisa e Ensino e Transportes (ANPET). Belém, PA, Brasil, 27.

Simão, G.L., Freitas, A.F., Silva, E. A., Bastos, B.R.N., Salgado, R.J, S.F. \& Amoedo, N.B.P. (2017). Políticas públicas de desenvolvimento local e adensamento de capital social: Análise do programa de aquisição de alimentos (PAA) em quatro municípios de Minas Gerais. Revista de Administração da UFSM, 10 (2), 288-306. 
Smart Growth America. (n.d.). Complete Streets Stimulate the Local Economy. Washington, DC: author. Retrieved from http://www.smartgrowthamerica.org/documents/cs/factsheets/cs-economic.pdf

Storper, M.; \& Venables, A. J. B. (2004). Buzz: face-to-face contact and the urban economy. Journal of Economic Geography, 4(4), 351-370. Retrieved from http://cep.lse.ac.uk/pubs/download/dp0598.pdf

Tribuna do Ceará (2016, 17 de dezembro). Ciclofaixa de lazer tem novas rotas neste domingo. Fortaleza, CE: author. Disponível em http://tribunadoceara.uol.com.br/noticias/mobilidadeurbana/ciclofaixa-de-lazer-temnovas-rotas-neste-domingo/

Weigand, L. (2008). A review of literature: the economic benefits of bicycling. Center for Transportation Studies. Center for Urban Studies. Portland State University, Portland, Oregon. $\quad$ Retrieved from https://www.pdx.edu/ibpi/sites/www.pdx.edu.ibpi/files/Economic\%20Benefits\%20of\%20 Bicycling.pdf.

Submetido em: 08.06 .2020

Aceito em: $\quad 28.08 .2020$ 